\title{
Correction to: Petitions of the Jewish Poor
}

\section{MARK COHEN}

Princeton University, Princeton, NJ, USA

E-mail: mrcohen@princeton.edu

\section{Correction to: Jewish History https://doi.org/10.1007/s10835-019-09317-3}

Figures 1 and 2 should have been published in the above-mentioned article. The omitted figures and figure captions appear on the next pages. 


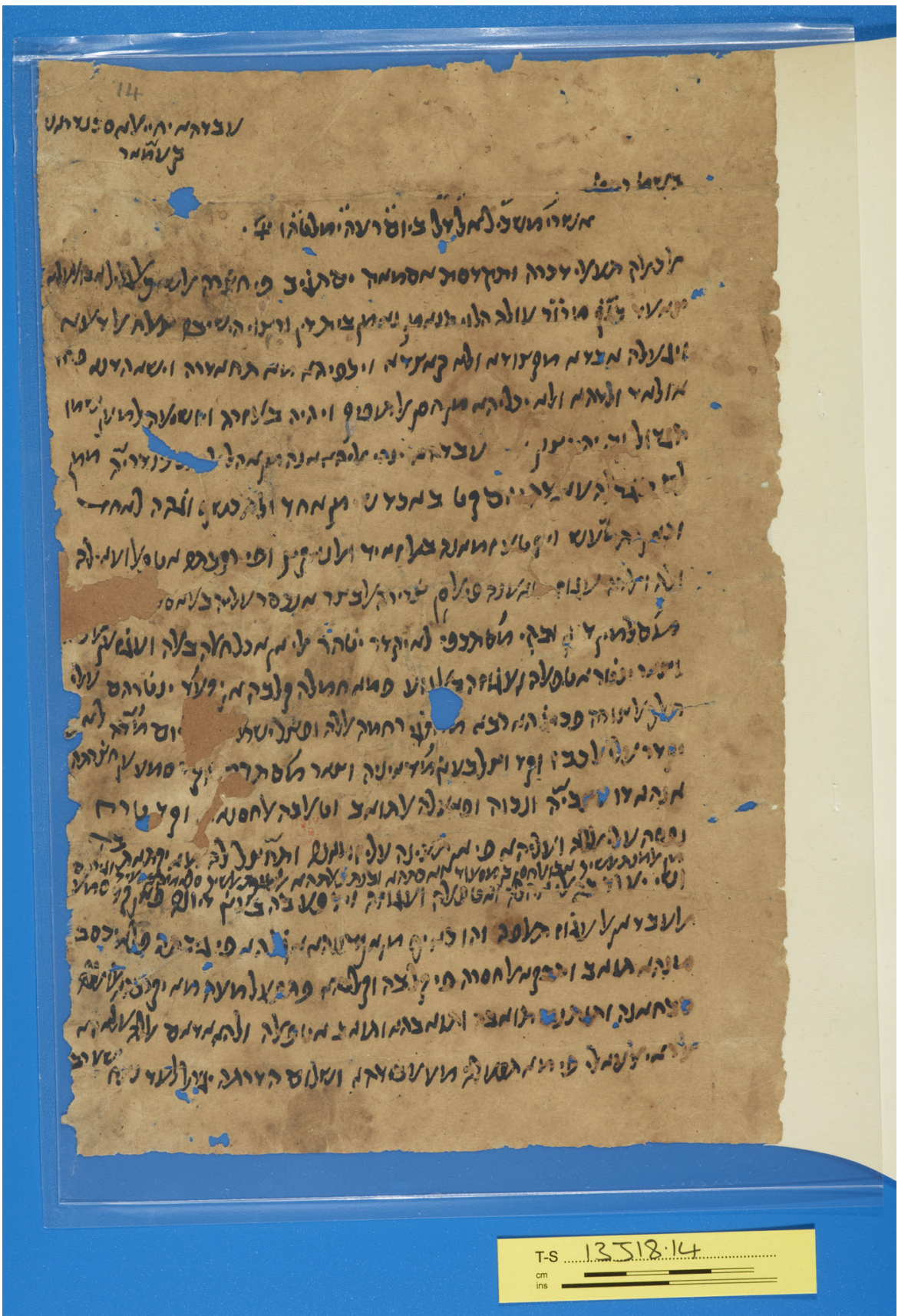

Figure 1. Cambridge University Library T-S 13J18.14 recto. Reproduced by kind permission of the Syndics of Cambridge University Library. 


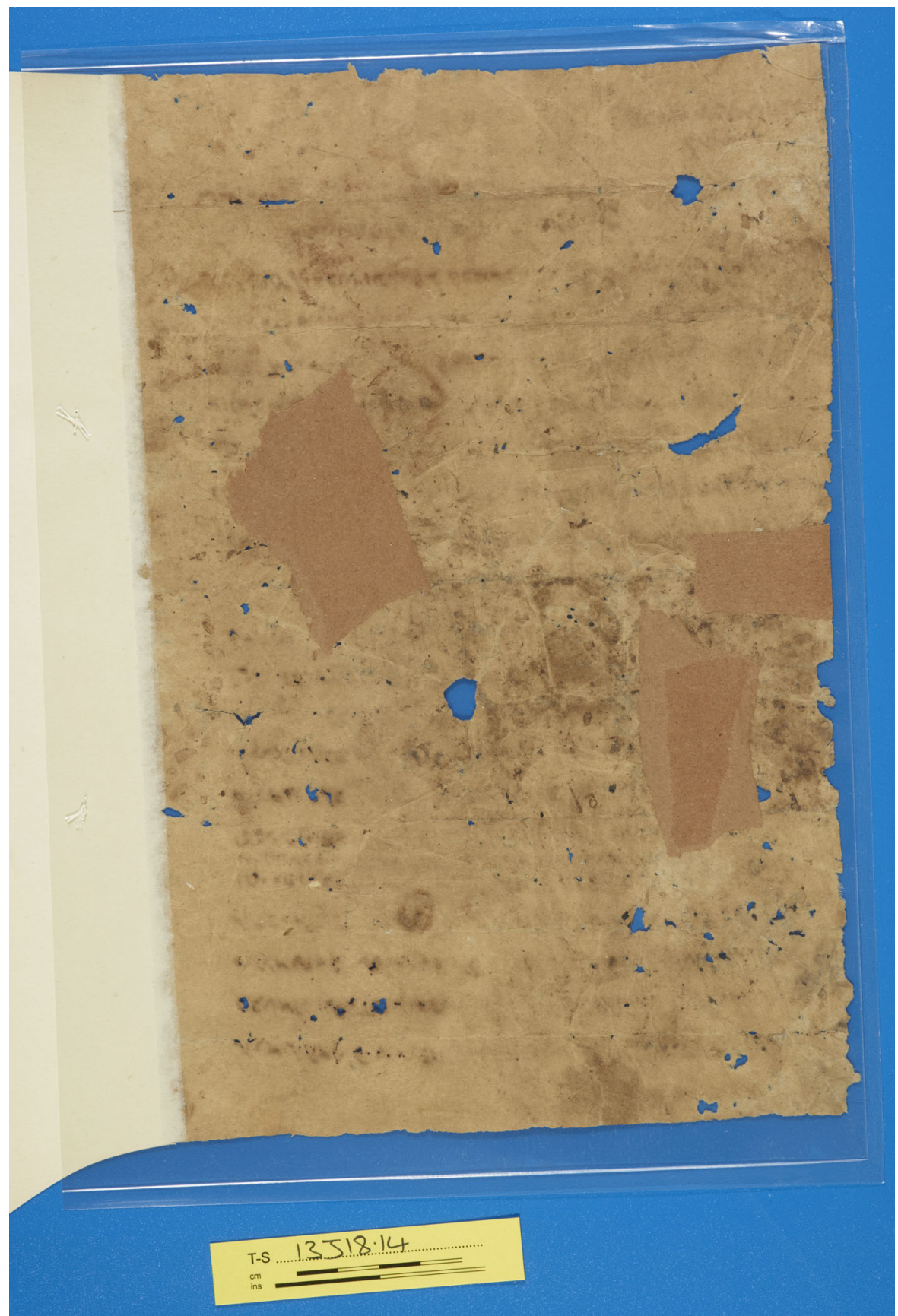

Figure 2. Cambridge University Library T-S $13 \mathrm{~J} 18.14$ verso. Reproduced by kind permission of the Syndics of Cambridge University Library. 
Publisher's Note Springer Nature remains neutral with regard to jurisdictional claims in published maps and institutional affiliations. 